\title{
Confidence, Evidence, and Disagreement
}

\author{
Katia Vavova
}

Received: 3 February 2013/ Accepted: 3 February 2013

(C) Springer Science+Business Media Dordrecht 2013

\begin{abstract}
Should learning we disagree about $p$ lead you to reduce confidence in $p$ ? Some who think so want to except beliefs in which you are rationally highly confident. I argue that this is wrong; we should reject accounts that rely on this intuitive thought. I then show that quite the opposite holds: factors that justify low confidence in $p$ also make disagreement about $p$ less significant. I examine two such factors: your antecedent expectations about your peers' opinions and the difficulty of evaluating your evidence. I close by proposing a different way of thinking about disagreement.
\end{abstract}

\section{Introduction}

Disagreements can be disturbing. And not just because they are typically unpleasant affairs. Disagreements can be epistemically disturbing. Learning that a respected peer disagrees with you can make you lose confidence in or altogether abandon your belief in the disputed proposition. But should it?

Most everyone now agrees that awareness of peer disagreement should sometimes lead you to revise your opinion. ${ }^{1}$ Everyone also agrees that disagreement isn't always significant. In particular, some think that if you are really sure of what you believe (and you're right in being so sure), then you shouldn't revise it just because we disagree. We might cash this out more carefully as follows:

\footnotetext{
1 You take me to be your peer about $p$ just in case you respect my opinion about $p$ as much as your own. If someone were to inquire, "Whom should I ask about $p$ ?" you'd say, "Ask me or ask her. It doesn't matter. We are equally likely to be right." Cf. Elga (2007).
}

K. Vavova $(\bowtie)$

Mount Holyoke College, 50 College St., 217B Skinner Hall, South Hadley, MA 01075, USA

e-mail: evavova@mtholyoke.edu 
The Intuitive Thought. How you ought to revise your opinion in the face of disagreement depends on how rationally confident you are in that opinion. The more rationally confident you are, the less you must revise.

In the most extreme case, when you are rationally maximally confident in some $p$, your confidence in $p$ needn't budge all in the face of disagreement.

The goal of this paper is twofold: to show that this prima facie plausible thought is wrong, and to suggest another, better, way of thinking about disagreement. I will first argue that even if you're really sure of what you believe and you're right in being so sure, discovering peer disagreement can still require you to revise. So the Intuitive Thought is false. I show that even our most confidently held beliefs aren't safe from disagreement. This is bad news for those who like the Intuitive Thought. But it isn't just the letter of the Intuitive Thought that's wrong. It is also wrong in spirit. To show this, I demonstrate how having a rational low confidence in $p$ can make disagreement about $p$ less significant. I then show how this initially surprising result can help us think about confidence, evidence, and disagreement.

\section{Background}

Most everyone now agrees that disagreement is sometimes significant. Consider following case:

Math. For years now, you have been meeting six friends for dinner every fortnight. You always split the check evenly, tipping $18 \%$ and rounding each person's share to the nearest dollar. The task of figuring out how much each person owes always falls on you and Smith. (You're the light drinkers in the group.) Upon receiving the check, you both do the requisite calculations in your head. Most of the time you agree. In the instances when you have disagreed, you have checked with a calculator and have been right equally often. Tonight you run the numbers and become quite confident that each share is \$43. But then Smith announces that she is quite confident that each share is $\$ 44$. Neither of you has had more wine or coffee, and you do not feel (nor does Smith appear) especially tired or especially perky. ${ }^{2}$

How confident should you now be that the shares are $\$ 43$ ? Less than you were before you learned of this disagreement.

This is a widely shared intuition. I think that it is right, and assume it is for the purposes of this paper. This is not a controversial assumption. Although few agree on why disagreement is significant, there is consensus disagreement is often significant in this way and in this type of case.

\footnotetext{
${ }^{2}$ Christensen (2009), Feldman (2006), (2007) and Elga (2007) present similar examples. All three hold that disagreement is often epistemically significant in exactly this sort of case. But even opponents of the kind of conciliatory views of disagreement that Christensen et al. favor, agree that revision is required in cases like Math. Cf. Kelly (2010), (2013), Lackey (2010a, b), and Sosa (2010). Possible exceptions include Weatherson (ms) and Kelly (2005).
} 
However, everyone also agrees that peer disagreement isn't always significant. For example, you do not need to revise your opinion in cases like this:

CrazyMath. As before, but Smith says that your shares are $\$ 385 .^{3}$

Consensus peters out as the cases become more complicated. Few agree on how to accommodate peer disagreement about difficult empirical matters, like whether the death penalty has deterrent effects, or controversial moral questions, like whether abortion is permissible. We might want a theory of disagreement to provide a plausible story about these more difficult cases. But such a theory should, at the very least, give us a principled way of distinguishing between the easy cases. It should rule that revision is required in cases like Math, but not in cases like CrazyMath.

\section{The Intuitive Thought: What it is and Why it Fails}

The Intuitive Thought suggests one way to do this. The proposal is that you needn't revise your confidence in $p$ just in case you are rationally highly confident in $p$, where:

To be rationally highly confident in $p$ is:

(a) to be highly confident in $p$, and

(b) for that to be the rational level of confidence to have in $p$ given the evidence. ${ }^{4}$

This thought provides some hope of explaining CrazyMath. After all, you are rationally highly confident in your belief that we each owe $\$ 43$ - or at least something in that ballpark. This is why you can ignore Smith's insane suggestion that you each owe $\$ 385$. It also gives us some hope of distinguishing CrazyMath from Math. Perhaps the case can be made that you aren't as rationally highly confident in your belief that your shares are $\$ 43$ in Math. This would explain why, in that case, you cannot ignore your peer's opinion.

But even if this prima facie plausible proposal could handle the easy cases, it ultimately fails. ${ }^{5}$ I will present two counterexamples to the Intuitive Thought. In the

\footnotetext{
${ }^{3}$ Cf. Christensen (2007) and Kelly (2010) among others.

${ }^{4}$ Lackey defends something like this view in her (2010a, b). In the latter, she writes:

At the heart of my justificationist view is the thesis that the amount of doxastic revision required in the face of peer disagreement tracks the amount of justified confidence present: the more justified and confident a belief is, the less doxastic revision is required, and the less justified and confident a belief is, the more doxastic revision is required (48-9).
}

Lackey later qualifies this statement in subtle ways that allow her to sidestep some counterexamples. Although important for understanding Lackey's view, these adjustments do not matter for my purposes here. Once I dispose of the Intuitive Thought as stated, I will argue that this focus on rational confidence is just the wrong way to approach the epistemic significance of disagreement.

5 For one, it isn't immediately obvious that the Intuitive Thought could help with the more difficult cases. It is clear what it would say: if you are rationally highly confident in your belief that abortion is permissible, then you needn't revise when someone disagrees with you. But one of the reasons these cases are difficult is that it isn't clear whether we can be rationally highly confident about such matters. Maybe there is more that the proponent of the Intuitive Thought could say here. Ultimately, it doesn't matter because the proposal succumbs to the following counterexamples. 
first, you are not rationally highly confident in your belief, and yet you can maintain confidence in the face of disagreement. In the second, you are rationally highly confident in your belief and yet you cannot maintain confidence in the face of disagreement. Together, these cases show that the letter of the Intuitive Thought is wrong. Rational high confidence does not protect against disagreement.

Consider the following version of Math:

BadMath. As before, but you are bad at math-especially percentages. Also, you are paranoid about undertipping servers. You get nervous when you have to calculate tips, which makes you even more prone to error. But you have finished your meal, and must calculate what you owe. You and your friend disagree: you say it's $\$ 43$, she says it's $\$ 385$.

As in CrazyMath, you should dismiss your friend's opinion and maintain your confidence. Of course, given how bad you are at math, you shouldn't be very confident that the right answer is $\$ 43$ to begin with. Still, this disagreement should not have much effect on whatever low confidence you do have. Notice that this is plausible even if you take your friend to be your epistemic superior-even if Smith is a mathematical genius who shares none of your financial neuroses. You are bad at math, yes, but isn't it more likely that Smith is joking or drunk, than that you each owe $\$ 385 ?^{6}$ This case shows that, contra the Intuitive Thought, you can sometimes dismiss peer disagreement about $p$ even though your antecedent confidence in $p$ is quite low.

But maybe this isn't the right version of the Intuitive Thought. Even if you're not rationally highly confident that you each owe $\$ 43$, you might be rationally highly confident in some related proposition; perhaps the proposition that you don't each owe hundreds of dollars, or the proposition that what you owe is much closer to $\$ 43$ than $\$ 385$. I think this much is right: you are more highly confident in these propositions and this is relevant to how you should respond to evidence of disagreement. Why not then amend the Intuitive Thought so that it picks out something like these propositions in which you are rationally highly confident?

I'm afraid this won't do, and here's why. Any version of the Intuitive Thought that affirms a direct relationship between some particular proposition (or kind of proposition) and the undermining effect of disagreement will either be false or a true but watered down, ad-hoc version of the original proposal. This is because, as I will show shortly, there is no straightforward relationship between how highly confident you are in some proposition and how much you ought to revise when you discover that there is disagreement (perhaps about some other proposition). Your rational confidence in the proposition that the right answer is not $\$ 385$ is grounded in a number of other factors essential to the explanation of why you can maintain confidence in the face of this disagreement. A true version of something resembling the Intuitive Thought would have to take all those factors into account. It would at best be a long, convoluted, and unhelpful claim.

I have now shown that having a rational low confidence in $p$ is compatible with rationally maintaining confidence in the face of disagreement about $p$. Now I will

\footnotetext{
${ }^{6}$ Christensen develops this kind of response to this case in his (2007). I will say a bit more about this shortly.
} 
show how having a rational high confidence in $p$ cannot protect $p$ from undermining by disagreement. Consider:

SuperMath. You are super at math. You are especially good at calculating percentages. You eat out a lot and rarely err at determining how much you owe. (Same for your friend; you are peers.) You crunch the numbers and disagree: you say $\$ 43$, she says $\$ 44$.

However reliable you might be, you are still fallible. Learning that your friend thinks half of the bill is $\$ 44$ rather than $\$ 43$ does not, in this case, give you any reason to think she is joking or drunk. SuperMath and Math are analogous in all respects except your level of confidence. Yet this does not make a difference: maintaining confidence seems wrong in both cases. SuperMath thus shows that disagreement can be undermining even when you are rationally highly confident in your belief.

If disagreement about $p$ can be significant despite your high confidence in $p$, and if it can be insignificant despite your low confidence in $p$, then the Intuitive Thought is wrong. Although your level of rational confidence is one determinant of the degree to which you should revise in light of disagreement, it is not the only one and its relevance is not as straightforward as the Intuitive Thought suggests. Furthermore, even if we did manage to identify other, less-than-straightforward ways in which level of confidence is relevant, there are, as we will now see, may other relevant factors too. The Intuitive Thought is the wrong way to think about disagreement. It oversimplifies matters and overstates the significance of rational confidence.

The same holds for principles like the Intuitive Thought, which try to distill a relation between the epistemic significance of disagreement and some one particular factor (be it rational high confidence or something else). These principles are analogous to the following claim: in response to evidence of cats, you should believe such-and-such. This suggestion is blatantly incomplete and shortsighted as a story about how to accommodate evidence of cats. Yet there is a temptation to make similar proposals with respect to evidence of disagreement. What I will show now is that we should resist this temptation. Things just aren't that simple when it comes to evidence and disagreement.

\section{How We Should Think About Evidence and Disagreement}

In the previous section I showed that the Intuitive Thought, as stated, is false. In this section I will show that nothing like it can be salvaged. The epistemic significance of disagreement depends on much more than rational confidence. In particular, it depends on, at least, our antecedent expectations about our peer's opinions and the difficulty of evaluating our evidence. Understanding how these factors affect the epistemic significance of disagreement can both show why simple principles like the Intuitive Thought are misguided and provide a better way of thinking about disagreement. 


\subsection{Evidence}

I'll begin with some nearly trivial points about evidence. I will then focus on evidence of disagreement.

Marbles. You have an urn filled with 100 marbles - some white, some black. You have some belief about the proportion of white to black marbles in the urn. You reach in and pick a random marble. It is black.

How surprised should you be that you picked a black marble on the first try? How should this discovery affect your belief about the contents of the urn?

It depends. If you antecedently believed that the urn contained only black marbles, then picking one on the first try should neither surprise you nor affect your belief about the contents of the urn (except, perhaps, to confirm it slightly). If instead you thought that the urn contained only white marbles, you should be shocked to discover a black marble, and must revise your belief about the urn's contents. Notice that this holds even if you were antecedently rationally highly confident that there were no black marbles in the urn. You should still revise if you pick a black marble, for you were obviously wrong about the urn's contents.

Suppose, instead, that you were antecedently confident that the urn contains more white marbles. Pulling a black one should surprise you. How much depends on further details of the case. But compare: if you had been confident that the urn contains an equal number of both black and white marbles, you wouldn't have been surprised whatever you had gotten. There was a $50 \%$ chance that you would pick a marble of that color.

The upshot is this: the more black marbles you antecedently believe are in the urn, the less surprised you will be to randomly pull one on the first try, and the less doing so should affect your opinion about the proportion of black marbles in the urn.

\subsection{Evidence of Disagreement}

Just as your shock at picking a black marble depends on your expectation about the proportion of black marbles, so your shock at discovering we disagree depends on your expectations about the proportion of disagreeing peers. Consider:

Peers. You believe $p$ and have 100 peers about $p$. You call a random peer. She says not- $p$.

Should you revise your opinion? That depends in part on how surprised you are to hear that your peer disagrees with you. And that depends on whether you expected to disagree at all and whether you expected to disagree like this.

Suppose that, before the disagreement, you were reasonably confident that all 100 of your peers would agree with you. (Perhaps you had data from the reputable Peer Survey Group.) If you are confident that all of your peers agree with you, you should be shocked to discover that the first person you randomly call disagrees. You should be shocked just as you were shocked to pull a black marble out of an urn supposedly full of white marbles. And you should revise your belief about the proportion of 
agreeing and disagreeing peers, just as you revised your belief about the proportion of black and white marbles.

\subsection{Confidence, Evidence, and Disagreement}

I have argued that disagreement's shock value correlates with whether you expect it. And the less you expect it the more you will have to revise your expectations when you get it. But the epistemic significance of disagreement depends on more than these expectations. It also depends on your evaluation of the state of your evidence.

To simplify, suppose there are just two reactions you might have to the evidence: you might think that it is clear or murky. Say you think it is clear. Then you can reasonably be fairly confident in whatever you conclude on its basis and you should expect agreement among peers. The evidence is clear, after all. Suppose instead you decide that the evidence is murky. Then you probably shouldn't be as confident in whatever you conclude on its basis and you should expect peer disagreement. After all, the evidence is murky.

This suggests a correlation among (at least) the following:

1. You evaluation of the state of evidence with respect to $p$.

2. Your estimate of the proportion of peers who believe that $p$.

3. The appropriate confidence to have in $p$.

If you discover that there is more disagreement than you expected, and are forced to revise your estimate of the proportion of peer disagreement, then you will also have to revise your opinion about the state of the evidence. (Probably, you overestimated its clarity.) And if you have to revise your opinion about the state of the evidence, you will have to revise the level of confidence you have in $p$. Likewise, if you get evidence that you are overconfident in $p$, you will have to revise your evaluation of the evidence as well as your antecedent estimate.

What this shows is that, contra the Intuitive Thought, your level of rational confidence is just one factor that feeds into how you ought to respond to evidence of disagreement. It also matters what your antecedent expectations are about the amount of agreement and the state of the original evidence. Of course, this isn't a complete story either. There are bound to be other factors that affect the epistemic significance of a piece of evidence. (Consider, for example, your level of rational confidence about these other factors: how sure are you that the evidence is clear? How sure are you that all your peers will agree with you?) I won't provide a complete list here of what factors are relevant to the epistemic significance of disagreement. Doing so would be akin to providing a list of what factors are relevant to the epistemic significance of a piece of evidence in general. It would be to give a theory of evidence. And I did not set out to complete such an ambitious task. What I have accomplished, however, can set us on the right track when thinking about disagreement, so that we can come up with some general heuristics to distinguish between the different sorts of cases with which we began. 


\section{How This Helps}

A theory of disagreement should explain why disagreement is significant when it is, and why it isn't when it isn't. It should also provide a principled way of dealing with our toy cases and a plausible account of the more realistic and difficult cases. I think evidence of disagreement is epistemically significant, when it is, because it is evidence of error. But I have not argued for that here. ${ }^{7}$ My aim has not been to provide a theory of disagreement. It has been to dislodge an intuitive but mistaken way of thinking about disagreement. By going back to the original cases, we can see how focusing on antecedent expectations rather than confidence alone gives us a better way of approaching evidence of disagreement.

\subsection{How to Handle the Cases}

We are now in a position to see how an approach like the one I advocate here might help get what we want out of a theory of disagreement. Such a theory should say that, in general, revision is required in cases like Math but not in cases like CrazyMath. Such a theory should also tell a plausible story about the more difficult cases of disagreement about controversial matters like abortion or the death penalty. Consider the easy cases first.

Why are you required to revise your opinion that half of the bill is $\$ 43$ when Smith says it's $\$ 44$ but not when she says it's $\$ 385$ ? Before you disagree, you conclude that each person owes $\$ 43$. The calculation was easy and you are confident in your answer. Since you take Smith to be your peer, you don't expect disagreement. Rightly so: if you are both good at math, and equally so, then disagreement is unlikely.

You should be surprised to learn that Smith's answer is $\$ 44$, but you should be shocked to learn that my answer is $\$ 385$. I have argued that disagreement can be more significant when it is more surprising. But the most surprising disagreement here seems to be the least significant. Is this a problem for what I have argued? No. This is the right result because the element of surprise is only part of the story about the epistemic significance of disagreement. The general lesson so far has been that the epistemic significance of disagreement depends, in part, on your antecedent expectations. I have focused mostly on the expectation of disagreement. But you have other expectations too. Crucially, you expect some ways of disagreeing more than others. You aren't shocked to learn that you and your friend's calculations were a couple of numbers off; you are shocked to learn that hers is in the 100s and yours is in the 10s. You reasonably assume that such extreme disagreement is unlikely between peers.

Notice, however, that you don't think it is unlikely because you are highly confident in your answer, but because you think that it is more likely that your friend is joking, lying, or drunk, than that she would actually arrive at an answer so far out of your ballpark. This is your doxastic state before you ever walk into the restaurant and take your first bite. Once you calculate and compare answers, you are rational in

\footnotetext{
7 This is an assumption of my paper. Cf. Elga (2007) and Christensen (2007, 2011), among others.
} 
thinking that she is pulling your leg. ${ }^{8}$ Notice that the same cannot be said about Math. You are initially confident in your answer, you don't expect disagreement, and you are surprised to find it. But you cannot explain it away as in CrazyMath. The disagreement in Math is newsworthy and the news isn't that your peer has lost it. It is that you might be wrong.

So it goes for the easy cases. It is easy to evaluate the evidence in these cases. It is also clear, what the evidence is, how to evaluate it, and how to assess our requisite abilities required for evaluating it. The fewer of these conditions that hold, the harder it will be to be confident in our opinions about the disputed matter. But, and this is the surprising result, it will also be easier to maintain whatever low confidence we do have.

What about the more difficult and realistic cases? Consider the question of whether the death penalty has deterrent effects. Maybe it is clear what the relevant evidence is: graphs and charts of crime rates in various States. Maybe it is also clear how to evaluate it: using statistics. It may even be clear how to assess the requisite abilities: there are better and worse statisticians. It may nevertheless be difficult to evaluate the evidence. Maybe there are too many charts and graphs. Or maybe our political leanings blind and bias us.

It gets worse for even more difficult moral questions. The evidence will typically be murky in hard cases like these, so we should expect to have a lower confidence and less agreement. Thus in the difficult cases, disagreement will typically be old news. Those who are aware of the murky evidential situations, and have appropriately revised their confidence, will not need to revise further upon meeting a disagreeing peer. They have already accommodated the evidence of error that they would have gotten from disagreement.

In the easy cases, on the other hand, the evidence will typically be clear. So we should expect to have both a high confidence and considerable peer agreement. Disagreement will thus typically be newsworthy and revision will usually be required. Disagreement can be evidence of our own error in the easy cases partly because we sometimes make simple mistakes about easy matters. That's when it is most helpful to use peers as "checks" on our thinking. ${ }^{9}$ If, on the other hand, our confidence is already low as in the difficult cases, if we are appropriately humble, we will may already checked our own thinking. And if so, then we won't have to revise further.

It is crucial to notice that the considerations that allow disagreement to be less epistemically significant in the difficult cases are the same considerations that mandate that the belief in question can only be maintained very weakly. A theory of disagreement that appropriately takes into account these insights is one that requires being already humble with respect to the difficult cases. It mandates a kind of humility about many a difficult questions and it does so antecedently to any actual disagreement. I think that this has significant independent plausibility. Most of us are irrationally overconfident in our beliefs about difficult factual, political, moral,

\footnotetext{
${ }^{8}$ Christensen (2007) develops this kind of response to the CrazyMath case. What I say here helps buttress that approach.

${ }^{9}$ Cf. Christensen (2007).
} 
and philosophical issues-in other words, about issues with murky evidential situations. There is epistemic work for disagreement in those areas where we are overconfident. There, disagreement is newsworthy, and there, it can indirectly lead us to revise our beliefs. But it need not do so for the already humble. For them, disagreement is old news.

An important implication of these results is that we might be able to mitigate some of the skeptical consequences often thought to result from taking evidence of disagreement seriously. ${ }^{10}$ The worry is that there is a lot of disagreement out there: if it is epistemically significant, then it will turn out that we aren't rational in believing much of anything. But, as I have argued, some of those beliefs about which there is most disagreement are also those beliefs in which we should already have low confidence. Since in such cases, the disagreement will be old news, it won't require further revision. Disagreement has greater undermining potential for those beliefs in which we are most rationally confident. But we rarely encounter disagreement about these sorts of beliefs. So the skeptical consequences of taking disagreement seriously aren't so radical after all.

\section{Conclusion}

I have argued that having a low confidence in $p$ can make your opinion about $p$ more resilient in the face of disagreement. This is a surprising claim that seems at odds with the Intuitive Thought that being rationally highly confident in $p$ can make your opinion immune to undermining by disagreement. But I have shown, on independent grounds, that the Intuitive Thought is false. And I have told a fairly uncontroversial story about the epistemic significance of a piece of evidence-any piece of evidence - that points the way toward a better way to think about the epistemic significance of disagreement. I have also shown how embracing this more nuanced way of thinking about disagreement can help mitigate the worry that taking disagreement seriously will lead to skepticism. There is room, then, after all, for humble belief in the face of controversy.

Acknowledgments This paper has benefited from many comments and conversations. I would particularly like to thank the following: Rachael Briggs, David Christensen, Tom Dougherty, Shamik Dasgupta, Adam Elga, Catherine Elgin, Caspar Hare, Sophie Horowitz, Thomas Kelly, Hilary Kornblith, Leon Leontyev, Heather Logue, Elisa Mai, Alejandro Pérez Carballo, David Plunkett, Paulina Sliwa, Agustín Rayo, Paolo Santorio, Bob Stalnaker, Judith Jarvis Thomson, Kenneth Walden, Roger White, Stephen Yablo and audiences at Duke University, Mount Holyoke College, MIT, the Pacific APA in Seattle (2010), the University of Kentucky, and the University of North Florida.

\section{References}

Christensen, D. (2007). Epistemology of disagreement: The good news. Philosophical Review, 116, $187-217$.

Christensen, D. (2009). Disagreement as evidence: The epistemology of controversy. Philosophy Compass, 4(1), 1-12.

${ }^{10}$ Cf. Kornblith (2010). 
Christensen, D. (2011). Disagreement, question-begging, and epistemic self-criticism. Philosopher's Imprint, 11(6), 1-22.

Elga, A. (2007). Reflection and disagreement. Noûs, 41, 478-502.

Feldman, R. (2006). Epistemological puzzles about disagreement. In S. Hetherington (Ed.), Epistemology futures (pp. 216-236). New York: Oxford University Press.

Feldman, R. (2007). Reasonable religious disagreements. In L. Antony (Ed.), Philosophers without Gods (pp. 194-214). Oxford: Oxford University Press.

Kelly, T. (2005). The epistemic significance of disagreement. In T. S. Gendler \& J. Hawthorne (Eds.), Oxford studies in epistemology (Vol. 1, pp. 167-196). Oxford: Oxford University Press.

Kelly, T. (2010). Peer disagreement and higher order evidence. In R. Feldman \& T. Warfield (Eds.), Disagreement (pp. 111-174). Oxford: Oxford University Press.

Kelly, T. (2013). Disagreement and the burdens of judgment. In D. Christensen \& J. Lackey (Eds.), The epistemology of disagreement: New essays. Oxford: Oxford University Press.

Kornblith, H. (2010). Belief in the face of controversy. In T. Warfield \& R. Feldman (Eds.), Disagreement (pp. 29-52). Oxford: Oxford University Press.

Lackey, J. (2010a). A justificationist view of disagreement's epistemic significance. In A. Haddock, A. Millar, \& D. Pritchard (Eds.), Social epistemology (pp. 298-325). Oxford: Oxford University Press.

Lackey, J. (2010b). What should we do when we disagree? In T. Szabó Gendler \& J. Hawthorne (Eds.), Oxford studies in epistemology (Vol. 3, pp. 274-293). Oxford: Oxford University Press.

Sosa, E. (2010). The epistemology of disagreement. In A. Haddock, A. Millar, \& D. Pritchard (Eds.), Social epistemology (pp. 278-297). Oxford: Oxford University Press.

Weatherson, B. (ms.) Do Judgments Screen Evidence? available at http://brian.weatherson.org/JSE.pdf. 